
\title{
25 Research Soure \\ Effects of Cerebrospinal Fluid AMPA Receptor Levels on the Clinical Efficacy of Lamotrigine in the Treatment of Epilepsy
}

\section{Qingjing Tan}

the First Affiliated Hospital of Guangxi University of Chinese Medicine

Yonghui Liu (D15994317559@126.com)

the First Affiliated Hospital of Guangxi University of Chinese Medicine https://orcid.org/0000-0002-

1738-4149

\section{Tianlu Wei}

Guangxi University of Chinese Medicine

\section{Junwei Yang}

the First Affiliated Hospital of Guangxi University of Chinese Medicine

\section{Tianbao Wang}

the First Affiliated Hospital of Guangxi University of Chinese Medicine

Haohai Lin

the First Affiliated Hospital of Guangxi University of Chinese Medicine

\section{Research article}

Keywords: Lamotrigine, Epilepsy, AMPA receptor

Posted Date: June 19th, 2019

DOI: https://doi.org/10.21203/rs.2.10367/v1

License: (c) (i) This work is licensed under a Creative Commons Attribution 4.0 International License.

Read Full License 


\section{Abstract}

Abstract Background $\triangle$ Epilepsy is one of great health burden in the world, deeply effects epilepsy population's mental and physical health,some can totally recover through effective treatment, while some others are difficult to recover even have life risks when seizure attacks. In that case,we explore the effects of cerebrospinal fluid AMPA receptor levels on the clinical efficacy of lamotrigine in the treatment of epilepsy.We believe our work might have an implication in the treatment of epilepsy. Methods $邓 T h e 70$ cases of epilepsy in our hospital were diagnosed and selected in this study from December 2016 to October 2018; The AMPA receptor content of patients in cerebrospinal fluid were determined by enzyme linked immunosorbent assay; The patients were paired into high AMPA group $(n=34)$ and low AMPA group ( $n=36$ ) according to the median value at $4.08 \mathrm{ng} / \mathrm{ml}$. Clinical efficacy and the incidence of adverse reactions were compared between two groups. Results $₫$ Before treatment, there was no significant difference in seizure frequency between the two groups ( $P>0.05)$; After treatment for 6 months and 12 months, the seizure frequencies of the two groups were gradually reduced $(P<0.05)$; Moreover, the number of seizures in the low AMPA group were significantly less than those in the high AMPA group $(P<0.05)$; The response rate of high AMPA group was $79.41 \%$, which was significantly lower than that in the low group AMPA ( $\chi 2=6.055, P=0.048)$; The improvement on the efficiency of electroencephalogram in the high AMPA group was $67.65 \%$, which was significantly lower than that in the low AMPA group $(x 2=4.686$, $P=0.030) ;$ However, there was no significant on the incidence of adverse reactions between two groups $(X 2=0.202, P=0.653)$. Conclusions $₫$ AMPA receptor plays an important role in the development of epilepsy

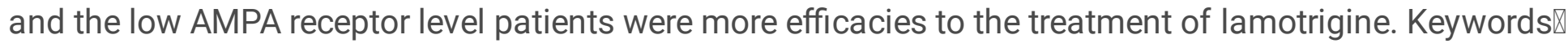
Lamotrigine; Epilepsy; AMPA receptor.

\section{Background}

Epilepsy is a disorder characterized by chronic and recurrent transient brain dysfunction syndrome, is a relative common neurological disorder worldwide ,a systematic analysis showed that there is approximately 45.9 million epilepsy patients around global, and the year of 2016 age-standardised rates increased $5.6 \%$ compared with 1990, the incidence rates is around 25/1000 capita $\varangle$ which is follow to the incidence rates of stroke $\mathrm{e}^{[1]}$. Although there are increasing option treatments for epilepsy,pharmacological treatment still remains the first choice to control epilepsy. Lamotrigine(LTG) belongs to Benzotriazine derivatives,is a novel broad -spectrum antiepileptic drugs (AEDs) widely used in the treatment of partial

and generalized seizures as monotherapy ${ }^{[2]}$, also can be an add-on therapy among children above 2 years and adults epilepsy with positive clinical tolerability.Lamotrigine is widely used in epilepsy population since it's efficacy and safety have been profoundly approved after many years'clinical observation. Currently,although some Chinese researchers have devoted themselves into the improvement of epilepsy treatment options, there are rare reports about studies on mechanisms between neurotransmission receptors and AEDs .The alpha-amino-3-hydroxy-5-methyl-4-isoxazole propionic acid(AMPA) receptor are the one of major mediators of glutamate-mediated excitatory neurotransmission , hyperactivation of AMPA receptor can provoked many acute neurologic function injury which could be the underlying 
mechanism of seizure onset ${ }^{[3,4]}$. Hence, we recruited 70 epilepsy patients who seek medical treatment in our hospital, study the effects of cerebrospinal fluid AMPA receptor levels on the clinical efficacy of Lamotrigine in the treatment of epilepsy, and provide clinical evidence to improve epilepsy's treatment.

\section{Methods}

\section{Materials}

We recruited 70 epilepsy patients in the encephalopathy department of the first affiliated hospital of Guangxi university of Chinese medicine during December 2016 to October 2018, which includes 42 male cases and 28 female cases,age are between 18 years old to 63 years old, average age $(42.19 \pm 12.80)$ years old, disease course between half year to 12 years, average disease course $(5.29 \pm 2.42)$ years. We classified these patients into generalized-onset (46 cases) and partial-onset(24 cases) according the International League Against Epilepsy (ILAE) classification ${ }^{[5]}$. All the recruited patients accordant to the following criteria: $\triangle$ Completeness of the initial accurate diagnosis of epilepsy base on clinical manifestation, regular electroencephalogram (EEG) and/or video EEG; $₫$ Naïve to other AEDs before treatment or intolerability AEDs due to high adverse effects ; $₫$ No apparent impairment of heart, lung, hepatic and renal organs,absense of other serious disease ,progressive nervous system disease and mental disease; $\varangle$ No history of alcohol dependence and drug abuse; $₫$ No contraindications with the use

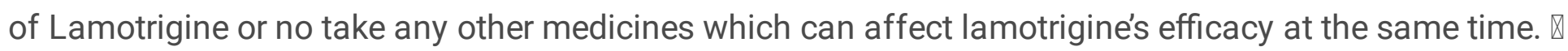
Females not in pregnancy and lactation. This study was approved by the Ethics Committees of the First Affiliated Hospital of Guangxi University of Chinese Medicine, all the patients and family provided informed consent to participant.

\section{Interventions}

Lamotrigine (trade name: Lamictal, purchased from GlaxoSmithKine,Tianjin,SFDA approval number:J20130026冈50 mg per table ). The initial dosage is prescribed at $12.5 \mathrm{mg}$ daily, then uptitrated to dosage of $25 \mathrm{mg}$ in ten days,twice a day; During experiment, dose adjustment was according to the seizure frequency, increment dosage of 12.5.mg every ten days until reach dosage of $100 \mathrm{mg}$ to $200 \mathrm{mg}$, twice a day ; The dosage was maintained once they reach the maximal efficacy. The treatment course lasts 12 months. Patients were tested blood routine, urine routine, hepatorenal function and immunity indication every 3 months. Patients were observed closely whether they had severe adverse effects such as allergic rash.

\section{Evaluation of Clinical Efficacy}

Generally, we depend on no seizure occur within one year to evaluate the efficacy of Lamotrigine ${ }^{[6]}$. In another perspective, we can also apply the EEG to help us evaluate the efficacy, base on the clinical criteria of electroencephalography ${ }^{[7]}$, the EEG is classified into: normal EEG of level first; mild abnormal EEG of level second ; moderate abnormal EEG of level third; severe abnormal EEG of level fourth. Classification of mild,moderate,and severe abnormal EEG are subject to abnormal EEG. If the EEG has 
been improved after treatment then is was regarded into effective, otherwise it was regarded into no effective.

\section{Measurement of CSF AMPA receptor content}

The CSF was collected by technique of lumber puncture, and was centrifuged for $10 \mathrm{~min}$ at 2,000 rpm immediately after it's collection and the supernatant was stored at a refrigerator in temperature below $80^{\circ} \mathrm{C}$ in order to avoid repeat freeze thawing. The expression level of CSF AMPA receptor were measured by enzyme linked immunosorbent assay (ELISA )according to the manufacturers' instructions by laboratory technology employees, the kit was purchased from Shanghai Chaoyan Biotechnology Company Limited (article No.SEE803Hu).

\section{Statistical analysis}

We performed data analyses with SPSS (version 19.0), quantitative data analyses with mean \pm standard deviation. Comparative between two groups analysis with independent sample of Student-t test. Comparative between multi-group analyses with one-way analysis of variance. Numeration data analyses with constituent ratio, comparative between two groups analyses with Chi-squared $\left(\chi^{2}\right)$ test,size of test $(a=0.05)$.

\section{Results}

\section{Outcome of Measurement of CSF AMPA Receptor content}

The mean level of all patients AMPA receptor is $\nabla 6.19 \pm 2.21 \llbracket \mathrm{ng} / \mathrm{mL}$; According to the medium value of $4.08 \mathrm{ng} / \mathrm{mL}$, patients were divided into high AMPA group (34 cases, the level of AMPA $>4.08 \mathrm{ng} / \mathrm{mL}$ ) and low AMPA group (36 cases, the level of AMPA $\leq 4.08 \mathrm{ng} / \mathrm{mL}$ ).

\section{Basic information comparative between high AMPA group and low AMPA group}

Difference between two groups patient's age, gender, prodrome, seizure type, intracranial pressure,etc have no statistically significant $(P>0.05)$ (Table 1$)$

\section{Level of CSF AMPA receptor content impact on lamotrigine clinical efficacy}

The rate of high AMPA group patient no seizure recur is $79.41 \% \otimes 27 / 34 \llbracket$ within one year, which is apparently lower than low AMPA group 97.22\%§35/36ه. The difference have statistical significance. $\square \chi^{2}=6.055, P=0.048$ )(Table 2).

\section{Impact of CSF AMPA receptor concent on lamotrigine's treatment reflect on EEG}

Rate of abnormal EEG between high and low AMPA group have no statistical difference before treatment $\square \chi^{2}=0.005, P=0.942 \triangle$. However, rate of abnormal EEG on low AMPA group is $63.89 \%$ after treatment, 
apparently lower than high AMPA group(85.29\%), the difference have statistical significance $\square \chi^{2}=4.194$, $P=0.041$ (Table 3)

\section{Effects of CSF AMPA receptor content on lamotrigine 's adverse effects}

There was 9 cases happened adverse effects after treatment with lamotrigine , 5 cases in high AMPA( rate is $14.71 \%, 5 / 34$ ) and 4 cases in low AMPA(rate is $11.11 \%, 4 / 36$ ), difference have no statistical significance $\nabla \chi^{2}=0.202, P=0.653$ ).

\section{Discussion}

Glutamate receptor is a majority of excitatory neurotransmission receptor in the central nervous system among mammalian, it divided into ionotropic and metabotropic ${ }^{[8]}$.Specifically,ionotropic glutamate contains N-methyl-D-aspartate (NMDA) \AMPA receptor and kainite (KA) receptor, all of them are the main mediators in the brain function,such as synaptic transmission, long-term synaptic potentiation, synaptic plasticity and learning- memorizing and so on ${ }^{[9]}$.Previously studies have showed that AMPA receptor also belongs to chemical voltage-gate channel receptors. Activation of AMPA receptor can initiate the opening of ion channel immediately, excessive the influx of monovalent cation $\mathrm{Na}^{+} \square \mathrm{K}^{+}{ }^{+}$and cause depolarization of postsynaptic membrane ${ }^{[10]}$.At the same time, activation of AMPA receptor can also leads the influx of extracellular $\mathrm{Ca}^{2+}$ that trigger a cascade events of biochemical response which can change the characteristic of membrane and excessive the generation of long-term potentiation. In the research of pathology mechanism on epilepsy, researchers have discovered that AMPA receptor channel GluR2 subunit can be replaced by GluR1 subunit and GluR3 subunit, enhanced neuron uptake the $\mathrm{Ca}^{2+}$, provoked the brain injury in hippocampal area of CA1 and CA3 that trigger seizure frequency ${ }^{[3]}$.Additionally, injection of AMPA receptors inhibitor before seizure onset can brings a significant impact of neuroprotective function, which can decrease seizure frequency effectively ${ }^{[11]}$. All of this studies have fully indicated that AMPA receptor plays an important role in epilepsy's onset and progressive ,treatments target on AMPA receptors might be helpful to control seizure attack,

Lamotrigine is a Benzotriazine derivatives, a current novel broad -spectrum antiepileptic drugs (AEDs),mechanism of lamotrigine on treatment of controlling epilepsy includes the inhibition release of glutamate and aspartic acid, then selectively functions on $\mathrm{Na}^{+}$channel and block the binding of excitatory glutamate and it's receptors ${ }^{[12]}$. Our study rely on patient's CSF AMPA receptor content 's median value to paired into two groups, results have shown that after month 6 and month 12 in treatment of lamotrigine, all patients seizure frequency was gradually decreasing and confirm lamotrigine's value on epilepsy, which was consist with the previous studies ${ }^{[13,14]}$. Most importantly ,our study have also discovered that seizure frequency in low AMPA group apparently lower than high AMPA group, it elucidated that the level of AMPA receptor might have an impact during lamotrigine's treatment in epilepsy.At the same time, through extensive comparative between two group's clinical efficacy, we found that high AMPA group 's response rate and the rate of EEG's improvement were lower than low AMPA 
group. It further indicates that the less content of AMPA receptor, the better of clinical efficacy of lamotrigine.We hypothesize that it might contributed to low excitatory glutamate in low AMPA receptor, and lamotrigine selectively inhibit the neuron depolarization and high-frequency discharge in seizure lesions, stabilize neuron $\mathrm{Na}^{+}$channel, block the transmission of overexcitation synapse to postsynaptic membrane, then decrease the frequency of seizure and produce a positive clinical efficacy.In addition, the adverse effects between two groups have no significant difference, it suggested that the content of AMPA receptor have no impact on lamotrigine's safety and reliability.

As stated above, our study suggest that CSF AMPA receptor plays a significant role in epilepsy's onset and progressive, and low content of AMPA receptor is better in option of lamotrigine. The limitation of our study is about small case, short duration and no observation in long term.Further high-quality research is needed to fully evaluate the efficacy of CSF AMPA receptor effect on lamotrigine's treatment in epilepsy.

\section{Conclusions}

As mentioned above,AMPA receptor plays an important role in the development of epilepsy and the low AMPA receptor level patients were more efficacies to the treatment of lamotrigine.

\section{Abbreviations}

AMPA: alpha-amino-3-hydroxy-5-methyl-4-isoxazole propionic acid;LTG『lamotrigine; AEDs::antiepileptic drugs; ILAE:International League Against Epilepsy;EEG:electroencephalogram;CSF: cerebrospinal fluid; ELISA: enzyme linked immunosorbent assay; KA: kainite. NMDA:ionotropic glutamate contains N-methylD-aspartate.

\section{Declarations}

\section{Acknowledgements}

Not applicable

\section{Funding}

Not applicable

\section{Availability of data and materials}

All data will be secured in the hospital computer and will be available on request from the corresponding author. 


\section{Authors' contribution}

QJT an YHL conceived the idea, designed the study and produced the first draft of the study.YHL helped with the statistical analysis. TLW,JWY,TBW and HHL-all have provided intellectual content in the preparation and editing of the manuscript.All authors read and approved the final manuscript.

\section{Ethics approval and consent to participate}

The First Affiliated Hospital of Guangxi University of Chinese Medicine's Research Ethics Committee has approved the study and all the participants were provided written informed consent.

\section{Consent for publication}

Written informed consent was obtained from the patients for publication of this study and any accompanying data.

\section{Competing interests}

Authors declare no financial or non-financial interests.

\section{References}

[1]GBD 2016 Neurology Collaborators. Global, regional, and national burden of neurological disorders, 1990-2016: a systematic analysis for the Global Burden of Disease Study 2016. Lancet Neurol. 2019.

[2]Ramaratnam S, Panebianco M, Marson AG. Lamotrigine add-on for drug-resistant partial epilepsy. Cochrane Database Syst Rev. 2016. (6): CD001909.

[3]Di Bonaventura C, Labate A, Maschio M, Meletti S, Russo E. AMPA receptors and perampanel behind selected epilepsies: current evidence and future perspectives. Expert Opin Pharmacother. 2017. 18(16): 1751-1764.

[4]Chang P, Augustin K, Boddum K, et al. Seizure control by decanoic acid through direct AMPA receptor inhibition. Brain. 2016. 139(Pt 2): 431-43.

[5]Moshé SL, Perucca E, Ryvlin P, Tomson T. Epilepsy: new advances. Lancet. 2015. 385(9971): 884-98.

[6]Nevitt SJ, Tudur Smith C, Weston J, Marson AG. Lamotrigine versus carbamazepine monotherapy for epilepsy: an individual participant data review. Cochrane Database Syst Rev. 2018. 6: CD001031.

[7]Seneviratne U, Hepworth G, Cook M, D'Souza W. Can EEG Differentiate Among Syndromes in Genetic Generalized Epilepsy. J Clin Neurophysiol. 2017. 34(3): 213-221. 
[8]Greger IH, Watson JF, Cull-Candy SG. Structural and Functional Architecture of AMPA-Type Glutamate Receptors and Their Auxiliary Proteins. Neuron. 2017. 94(4): 713-730.

[9]Spampinato SF, Copani A, Nicoletti F, Sortino MA, Caraci F. Metabotropic Glutamate Receptors in Glial Cells: A New Potential Target for Neuroprotection. Front Mol Neurosci. 2018. 11: 414.

[10]Joshi S, Rajasekaran K, Sun H, Williamson J, Kapur J. Enhanced AMPA receptor-mediated neurotransmission on CA1 pyramidal neurons during status epilepticus. Neurobiol Dis. 2017. 103: 45-53.

[11]Rogawski MA. A fatty acid in the MCT ketogenic diet for epilepsy treatment blocks AMPA receptors. Brain. 2016. 139(Pt 2): 306-9.

[12]Mahfoz AM, Abdel-Wahab AF, Afify MA, et al. Neuroprotective effects of vitamin D alone or in combination with lamotrigine against lithium-pilocarpine model of status epilepticus in rats. Naunyn Schmiedebergs Arch Pharmacol. 2017. 390(10): 977-985.

[13]Sidhu HS, Srinivasa R, Sadhotra A. Evaluate the effects of antiepileptic drugs on reproductive endocrine system in newly diagnosed female epileptic patients receiving either Valproate or Lamotrigine monotherapy: A prospective study. Epilepsy Res. 2018. 139: 20-27.

[14]Campos M, Ayres LR, Morelo M, Carizio F, Pereira L. Comparative efficacy of antiepileptic drugs for patients with generalized epileptic seizures: systematic review and network meta-analyses. Int $\mathrm{J}$ Clin Pharm. 2018. 40(3): 589-598.

\section{Tables}

\begin{tabular}{|c|c|c|c|c|}
\hline & $\begin{array}{l}\text { high AMPA } \\
\text { group }\end{array}$ & $\begin{array}{l}\text { Low AMPA } \\
\text { group }\end{array}$ & $\begin{array}{l}t / \chi^{2} \\
\text { vaule }\end{array}$ & $\begin{array}{l}\mathrm{P} \\
\text { vaule }\end{array}$ \\
\hline Age (year) & $40.95 \pm 13.06$ & $43.51 \pm 11.93$ & 0.857 & 0.395 \\
\hline Gender (male/female) & $19 / 15$ & $23 / 13$ & 0.467 & 0.494 \\
\hline Prodrome & & & 0.508 & 0.917 \\
\hline Fever & 22 & 23 & & \\
\hline Abdominal pain and diarrhea & 3 & 4 & & \\
\hline Cold sore & 2 & 1 & & \\
\hline No symptoms & 7 & 8 & & \\
\hline Seizure type & & & 0.827 & 0.843 \\
\hline Generalized onset & 2 & 3 & & \\
\hline Simple partial onset & 1 & 3 & & \\
\hline Complex partial onset & 1 & 3 & & \\
\hline $\begin{array}{l}\text { Partial secondary generalized } \\
\text { onset }\end{array}$ & 30 & 29 & & \\
\hline Intracranial pressure & & & 0.183 & 0.669 \\
\hline normal & 13 & 12 & & \\
\hline abnormal & 21 & 24 & & \\
\hline
\end{tabular}


Table 1 Basic characteristic comparative between high AMPA group and low AMPA group

case(n) no recur within one year rates of no recur within one year $\chi^{2}$ value

PA 34

27

$79.41(27 / 34)$

$6.055 \quad 0.048$

?A 36

35

$97.22(35 / 36)$

Table 2.Level of CSF AMPA receptors impact on lamotrigine clinical efficacy

\begin{tabular}{|c|c|c|c|c|c|c|c|}
\hline & group & case $\square \mathrm{n} \square$ & प & प & प & $\square$ & Rate of abnormal $\square \square$ \\
\hline & High AMPA & 34 & 3 & 14 & 10 & 7 & $91.18 \square 31 / 34 \square$ \\
\hline \multirow[t]{3}{*}{ Before treatment } & Low AMPA & 36 & 3 & 13 & 12 & 8 & 91.67ロ33/36ロ \\
\hline & $\chi^{2}$ value & & & & & & 0.005 \\
\hline & $P$ value & & & & & & 0.942 \\
\hline \multirow[t]{4}{*}{ After treatment } & High AMPA & 34 & 5 & 16 & 8 & 5 & $85.29 \llbracket 29 / 34 \square$ \\
\hline & Low AMPA & 36 & 13 & 15 & 5 & 3 & 63.89₫23/36₫ \\
\hline & $\chi^{2}$ value & & & & & & 4.194 \\
\hline & $P$ value & & & & & & 0.041 \\
\hline
\end{tabular}

Table 3 Impact of CSF AMPA receptors content on lamotrigine's treatment reflect on EEG 